\title{
Participatory Budgeting: Could It Diminish Health Disparities in the United States?
}

\author{
Carolin Hagelskamp (D) - David Schleifer • Chloe Rinehart • \\ Rebecca Silliman
}

Published online: 7 May 2018

(C) The New York Academy of Medicine 2018

\begin{abstract}
Participatory budgeting (PB) - a democratic process where ordinary residents decide directly how to spend part of a public budget - has gained impressive momentum in US municipalities, spreading from one pilot project in Chicago's 49th ward in 2009 to 50 active PB processes across 14 cities in 2016-2017. Over 93,600 US residents voted in a PB process in 20152016 , deciding over a total of about $\$ 49.5$ million and funding 264 projects intended to improve their communities. The vast majority of US PB processes take place
\end{abstract}

\begin{abstract}
About Public Agenda
Public Agenda is a nonprofit, nonpartisan organization. Through research and public engagement, Public Agenda seeks to help build a democracy that works for everyone. Public Agenda leads, conducts, and supports evaluation and research on participatory budgeting (PB) in the USA and Canada. In this function, Public Agenda collaborates with evaluation researchers and implementers of PB across US and Canadian municipalities, the national PB research board, and the nonprofit Participatory Budgeting Project. Public Agenda's research on PB has been supported by the Democracy Fund, the Rita Allen Foundation, and through a research partnership with the Kettering Foundation (more information at: www.publicagenda.org).
\end{abstract}

C. Hagelskamp $(\bowtie)$

Department of Public Administration, Berlin School of Economics and Law, Berlin, Germany

e-mail: carolin.hagelskamp@hwr-berlin.de

D. Schleifer $\cdot$ C. Rinehart $\cdot$ R. Silliman

Public Agenda, New York, NY, USA

D. Schleifer

e-mail: dschleifer@publicagenda.org in large urban centers (e.g., New York City, Chicago, Seattle, Boston), but PB has also recently spread to some smaller cities and towns [1]. Figure 1 illustrates the growth of PB processes in the USA, and within New York City and Chicago council districts specifically.

$\mathrm{PB}$ constitutes a rare form of public engagement in that it typically comprises several distinct stages that encourage residents to participate from project idea collection to project implementation (see Fig. 2). The decisive public vote in US PB is practically binding as elected officials commit to implementing the public decision at the outset of the process. Moreover, all current PB processes in the USA have expanded voting rights to residents under 18 years old and to non-citizens. Under President Obama, the White House recognized PB as a model for open governance. Participatory Budgeting Project, a nonprofit organization that advocates for PB, won the 2014 Brown Democracy Medal, which recognizes the best work being done to advance democracy in the USA and internationally.

PB has been lauded for its potential to energize local democracy, contribute to more equitable public spending and help reduce inequality $[2,3]$. Social justice goals have been explicit in US PB from the start. Grassroots advocates, technical assistance providers, and many elected officials who have adopted it emphasize that PB must focus on engaging underrepresented and marginalized communities $[2,4,5]$. PB steering committees have specified equity and inclusiveness goals in PB rule books $[6,7]$. The most conclusive research so far on PB's potential to reduce social inequalities, however, comes from Brazil, where PB started in 1989. In Brazil, $\mathrm{PB}$ has been associated with a reduction in extreme 


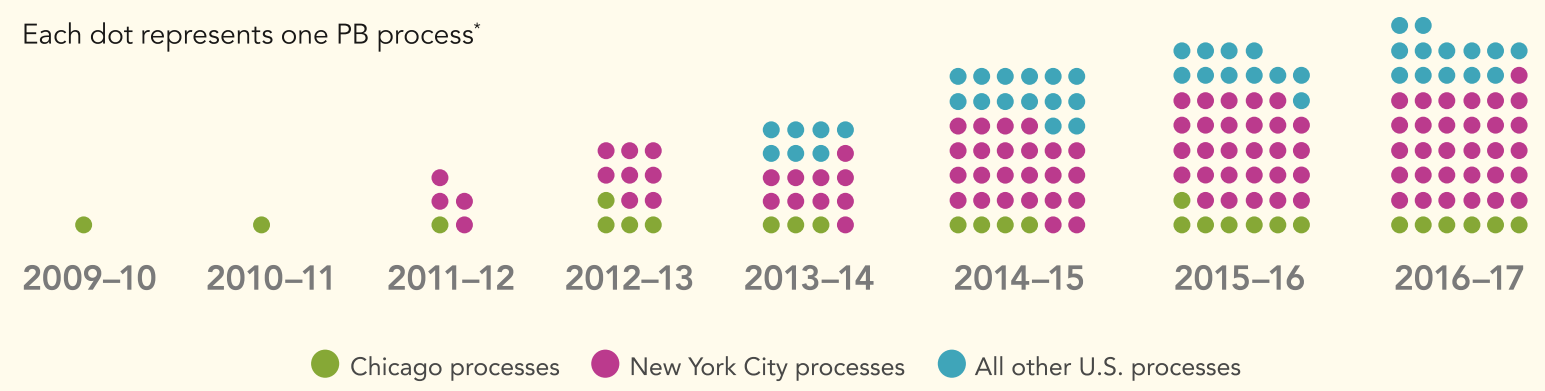

Source: Public Agenda, Participatory Budgeting Project.

"These counts include only PB that was implemented by a city council, council member or city agency. It does not include school- or collegewide PB processes.

Fig. 1 Participatory budgeting in the USA has grown from 1 process in 2009-2010 to 50 processes in 2016-2017

poverty, better access to public services, greater spending on sanitation and health services, and, most notably, a reduction in child and infant mortality $[8,9]$.

In this paper, we outline three mechanisms by which PB could affect health disparities in US municipalities: First, by strengthening residents' psychological empowerment; second, by strengthening civic sector alliances; and third, by (re)distributing resources to areas of greatest need. We summarize the theoretical argument for these impacts, discuss the existent empirical evidence, and highlight promising avenues for further research.

\section{PB, Psychological Empowerment, and Health}

To the extent that PB offers new opportunities for political participation, it could diminish health disparities. Some forms of political participation and civic engagement have been linked to positive health and well-being outcomes [10, 11]. In particular, political participation and civic engagement can promote individuals' psychological empowerment - that is, residents' can gain a greater sense of personal and collective efficacy, including the feeling that they can make a difference in their communities, and residents can develop greater civic skills, civic knowledge, and social and political awareness $[11,12]$. Psychological empowerment has been linked to better mental health outcomes in research with adolescents [13, 14].
In order to reduce health disparities by means of psychological empowerment, PB needs to especially engage residents from communities that are known to experience comparatively worse health and well-being (e.g., low-income residents and people of color). Traditionally, marginalized communities may also benefit comparatively more from the potentially positive psychological effects of participation than socially and politically advantaged resident groups, who may already experience a comparatively high level of collective efficacy and civic skills. And for any of these longer-term benefits to occur, it is critical that engagement opportunities in PB are truly participatory, reduce barriers to participation, and that residents view the process as fair $[15,16]$.

Research into US PB so far has shown high voter turnout among lower income residents and people of color in many PB communities, but it also found substantial variability in communities' efforts and successes to engage residents from traditionally marginalized groups [17, 18]. In 2014-2015, in 61\% of PB communities that collected demographic data from voters, residents with annual household incomes of under $\$ 50,000$ were over-represented or represented at levels similar to the local census. African-American residents were overrepresented or represented at levels similar to the local census in $89 \%$ of communities that collected demographic information from voters [17]. PB organizers who worked with community-based organizations (CBOs) from the start to increase targeted outreach 


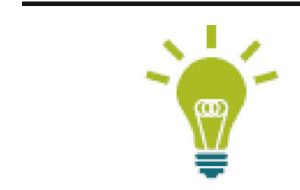

\section{Idea Collection}

Residents come together in public meetings and online to discuss community needs and brainstorm ideas for projects that could be financed with the money their public representatives have allocated to the PB process.

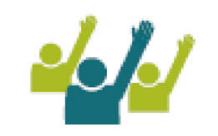

\section{Budget Delegates}

Resident volunteers work in groups (or committees) to develop the initial ideas into actual project proposals. These volunteers (commonly called budget delegates) typically work closely with relevant city agencies to assess the feasibility and cost of projects.

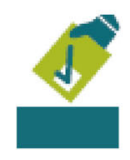

\section{Voting}

Fully developed project ideas are put on a ballot for residents-including youth and noncitizens - to vote on. The voting period often lasts several days.

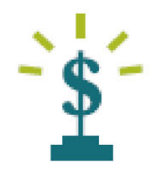

\section{Project Implementation}

Projects that get the most votes and fall within the cap of allocated funds win. Government commits to implementing winning projects.

Fig. 2 Typical stages of a participatory budgeting process in the USA

and reduce participation barriers for marginalized groups were more successful in turning out lower income residents and people of color at the vote, compared to PB organizers who did not collaborated with CBOs [17]. Offering more voting opportunities has also been associated with greater turnout of low-income residents and people of color $[1,17,18]$.

Future research should not only compare psychological empowerment, health, and well-being between PB participants and a control group over time, but also examine relationships between these critical outcomes and PB participants' personal experience of the varying qualities and characteristics of PB implementation across municipalities (e.g., their perception of fairness and inclusiveness of the process). Research further needs to examine whether participation at the idea collection or the delegate phases of $\mathrm{PB}$ - which require considerable time commitments and involve sustained 
work with other community members - have a different impact on individuals than participation at the voting stage only. As the former offer residents more sustained engagement opportunities, they should have more impact on psychological empowerment. Finally, empowerment theory suggests that individual health benefits in municipalities that regularly implement PB might go beyond effects on the most engaged participants to greater well-being for residents generally, by means of living in this politically more empowering context [11].

\section{PB, Civic Sector Alliances, and Health}

PB can empower communities beyond the individual level by offering opportunities for CBOs and other civic groups to meet and form alliances that can be leveraged beyond the PB process itself. CBO engagement in participatory political processes in Brazil has been linked to greater CBO mobilization and a strengthening of civic sector alliances [19]. In Brazil, CBOs could thus push more effectively and legitimately for policy changes, which in turn could be linked to measurable reduction in health disparities. PB may thus carry the potential to affect community-level changes in the form of a strengthened civic sector infrastructure and with that greater collective efforts to push for policy changes.

In the USA, PB advocates have also stressed the vital role $\mathrm{CBOs}$ have in realizing $\mathrm{PB}$ 's potential to reduce inequities. On the one hand, CBOs in the USA have from the start had a major role in engaging marginalized communities in PB. On the other hand, PB could strengthen CBOs by providing a context for organizations to meet and collaborate, and thus to build stronger ties among themselves and to improve their relationships with government. Those new relationships could in turn facilitate CBOs' ability to collectively advocate for policy changes that would help reduce health inequalities. Stronger alliances in the civic sector could also work to catapult PB out of often limiting budgetary structures to have greater impacts on inequities [2].

To date, there is no systematic research on PB's impacts on CBOs and CBO alliances in the USA. Some US officials report having observed new civic sector alliances forming or strengthening in their PB process [4]. More research is needed to shed light on how CBOs in current US PB districts evaluate the opportunities PB offers them, and how and to whose benefit civic sector alliances might develop over the coming years.

\section{PB, Resource (Re)Distribution, and Health}

The projects that win funding through $\mathrm{PB}$ constitute another important mechanism by which $\mathrm{PB}$ has the potential to reduce health disparities. $\mathrm{PB}$ can raise awareness of community needs that may be forgotten or invisible under politics-as-usual. If project ideas that benefit people of greatest need make it onto a PB ballot and win, $\mathrm{PB}$ could lead to a more equitable distribution of public funds than what would have been funded without PB. Even if projects of greatest need do not end up winning the $\mathrm{PB}$ vote, they may nevertheless inform elected officials' spending priorities elsewhere [4]. To the extent that funds that are distributed through or because of $\mathrm{PB}$ are more likely to benefit the health and well-being of disadvantaged residents, PB could, over time, contribute to a reduction of health disparities.

Many of the projects that received PB funding in recent years have the potential to affect community health outcomes. PB funds are typically restricted to capital projects. In the 2014-2015 and the 2015-2016 cycles, a large proportion of PB funds benefitted parks and recreation: 15 and $19 \%$ respectively. Moreover, a significant amount of PB funding has gone to streets, sidewalks, transportation, and traffic: $22 \%$ of dedicated PB money in 2014-2015 and 22\% in 2015-2016 [1, 17]. These are important and promising numbers given that both green spaces and recreation opportunities as well as street and traffic improvements can have important impacts on health inequalities in urban areas [20-22]. Large proportions of PB funds have also gone to schools especially for renovations and teaching and learning technology [1], thus potentially improving a critical context for young people's learning and development. However, current PB funds are still comparatively small and perhaps too small still to lead to projects that could by themselves affect health inequities long term.

A next step for this research is to better understand to what extent disadvantaged communities in particular are likely to benefit from these expenditures, and to develop valid and reliable ways to measure these impacts. For example, more work is needed to identify the most likely beneficiaries of PB-initiated park, street, and traffic improvements. And do these improvements increase 
health-promoting behaviors, increased feelings of safety and reduce accidents? We also need to understand to what extent PB expenditures differ from what elected officials have or would have funded without PB. Are, for example, the neediest schools receiving more resources with PB than they would have received without PB? Can these school investments be linked to greater well-being among students? Finally, we need to understand better how large investments need to be to lead to measurable effects long term.

\section{Conclusion}

We presented the theoretical argument for why and how US PB could impact health disparities long term in communities that adopt this political process. We described individual- and community-level pathways through which PB could improve the health and wellbeing of residents. However, whether PB's impacts will in fact follow the theoretical pathways outlined here depends on the quality and focus of its continued implementation. It is unlikely that PB will help reduce health disparities if such impacts are not explicit goals of the processes and considered in each step of its implementation. As we discussed, social justice motivations remain prevalent in US PB, but the quality of PB implementation varies. Moreover, it is likely that applying the process to larger and more diverse budgets will facilitate PB's potential impacts on health and wellbeing outcomes. The next few years will tell whether and under which conditions US PB can help reduce health disparities.

Acknowledgements The authors' research on participatory budgeting has been supported by the Democracy Fund (\# G-201408-01315) and the Rita Allen Foundation (\# NS-160701074) and completed through a research partnership with the Kettering Foundation (\# 35.26.00, KF-55453).

\section{References}

1. Hagelskamp C, Rinehart C, Silliman R, Schleifer D. A process of growth. The expansion of participatory budgeting in the United States and Canada in 2015-16. New York: Public Agenda; 2016. https://www.publicagenda. org/pages/a-process-of-growth. Accessed 15 Sept 2017.

2. Pape M, Lerner J. Budgeting for equity: how can participatory budgeting advance equity in the United States? J Public
Deliberation. 2016;12(2) http://www.publicdeliberation. net/jpd/vol12/iss2/art9. Accessed 15 Sept 2017.

3. Fung A, Wright EO. Deepening democracy: institutional innovations in empowered participatory governance. Memphis, Tennessee: Verso; 2003.

4. Hagelskamp C, Schleifer D, Rinehart C, Silliman R. Why let the people decide? Elected Officials on Participatory Budgeting. New York: Public Agenda; 2016. https://www. publicagenda.org/pages/why-let-thepeople-decide. Accessed 15 Sept 2017.

5. Lerner J, Secondo D. By the people, for the people: participatory budgeting from the bottom up in North America. $J$ Public Deliberation. 2012;8(2)

6. Su C. From Porto Alegre to New York City: participatory budgeting and democracy. N Pol Sci. 2017;39(1):67-75.

7. Leighninger M, Rinehart C. Brazil has reduced inequality incrementally - can we do the same? Gauging the potential of participatory budgeting in the United States and Canada. New York: Public Agenda; 2016. https://www. publicagenda.org/pages/brazil-has-reduced-inequalityincrementally. Accessed 15 Sept 2017.

8. Touchton M, Wampler B. Improving social well-being through new democratic institutions. Comp Polit Stud. 2014;47(10):1442-69.

9. Gonçalves $\mathrm{S}$. The effects of participatory budgeting on municipal expenditures and infant mortality in Brazil. World Dev. 2014;53:94-110. http://policydialogue. org/files/publications/Effects_of_Participatory_Budgeting. pdf. Accessed 15 Sept 2017.

10. Radcliff B, Shufeldt G. Direct democracy and subjective well-being: the initiative and life satisfaction in the American states. Soc Indic Res. 2016;128(3):1405-23.

11. Christens BD. Targeting empowerment in community development: a community psychology approach to enhancing local power and well-being. Community Dev J. 2012;47(4):538-54.

12. Christens BD, Peterson NA, Speer PW. Community participation and psychological empowerment: testing reciprocal causality using a cross-lagged panel design and latent constructs. Health Educ Behav. 2011;38(4):339-47.

13. Zimmerman MA, Ramirez-Valles J, Maton KI. Resilience among urban African American male adolescents: a study of the protective effects of sociopolitical control on their mental health. Am J Community Psychol. 1999;27(6):733-51.

14. Christens BD, Peterson NA. The role of empowerment in youth development: a study of sociopolitical control as mediator of ecological systems' influence on developmental outcomes. J Youth Adolesc. 2012;41(5):623-35.

15. Prilleltensky I. Wellness as fairness. Am J Community Psychol. 2012;49(1-2):1-21.

16. Christens BD. Toward relational empowerment. Am J Community Psychol. 2012;50(1-2):114-28.

17. Hagelskamp C, Rinehart C, Silliman R, Schleifer D. Public spending, by the people. Participatory budgeting in the United States and Canada in 2014-15. New York; 2016.

18. Kasdan A, Markman E. Participatory budgeting and community-based research: principles, practices, and implications for impact validity. N Polit Sci. 2017;39(1):143-55.

19. Coelho VSRP, Waisbich L. Participatory mechanisms and inequality reduction: searching for plausible relations. $J$ Public Deliberation. 2016;12(2) 
20. Hystad P, Davies HW, Frank L, van Loon J, Gehring U, Tamburic L, et al. Residential greenness and birth outcomes: evaluating the influence of spatially correlated built-environment factors. Environ Health Perspect. 2014;122(10):1095-102.

21. Dadvand P, Nieuwenhuijsen MJ, Esnaola M, Forns J, Basagaña X, Alvarez-Pedrerol M, et al. Green spaces and cognitive development in primary schoolchildren. Proc Natl Acad Sci. 2015;112(26):7937-42.

22. Anderson G, Searfoss L, Cox A, Schilling E, Seskin $\mathrm{S}$, et al. Safer streets, stronger economies: complete streets project outcomes from across the United States. ITE J. 2015:29-35. 